\title{
The Teaching Practice of "Database Principle and Application" Course Based on the Application of Innovative Ability
}

\author{
Jiang Xiuying \\ College of Information of Science and Engineering \\ Zaozhuang University \\ Zaozhuang, China \\ jiangxiuyingxyz@163.com
}

\author{
Lv Jiaguo \\ College of Information of Science and Engineering \\ Zaozhuang University \\ Zaozhuang, China \\ lvjiaguo2004@163.com
}

\author{
Chi Qingyun \\ College of Information of Science and Engineering \\ Zaozhuang University \\ Zaozhuang, China \\ 13806322990@163.com
}

\begin{abstract}
This paper analyzes the target of training courses, training innovative ability of students based on the teaching content, teaching mode, curriculum design, assessment methods, textbook reform and so on has carried on the beneficial exploration, introduces the self-compiled teaching textbook content and structure, main features and application. Pay attention to each teaching link of mutual penetration, achieved a better teaching result.
\end{abstract}

Keywords-Database application; Application innovation ability; Teaching mode; Teaching textbook construction

\section{INTRODUCTION}

Database technology is a computer data management technology developed in late 1960s, has been attracted much attention of people since birth to now is an important branch of computer science, and is also one of the most important branches of computer science and technology, which is the fastest and most widely used. It has become the important technical foundation and pillar of the computer information system and the computer application system.

"Database principle and application" is a required course of the college computer major. It is one of the 8 established professional core curriculum Steering Committee of science and technology of Ministry of education, computer teaching, is an equal emphasis on professional knowledge and practical ability of the curriculum. How to cultivate the students' innovate ability, improve the level of application of database technology in the process of curriculum construction for many years, reform is beneficial to the teaching mode, teaching content, curriculum design, textbook compilation and other aspects.

\section{INNOVATION ABILITY AND DATABASE APPLICATION COURSE TRAINING GOAL}

Innovation ability is a kind of behavior ability to improve or create new things, and can get some beneficial effect using existing knowledge and materials, in particular environment, the spirit of the ideal or to meet the needs of the society. The innovation ability is the soul of the national progress and the core of the economic competition. The cultivation of innovative ability refers to the influence, development and training of people's creativity, that is, the final product of Education -- the cultivation of innovative talents. So how to cultivate students' creative thinking is the main task for every teacher to carry out creative education.

This course focus on the cultivation of students' ability in database application, to enable students to master the design, database application system planning, deployment, implementation, development and management, and be able to engage in the development of information system and database management. Specifically, Students are required to master the theory of relational database and the whole process of database design, to master the basic concepts of SQL Server database management system and the basic operation of the database, to master SQL Server program design ideas and methods, can design database structure and application program, master the use of stored procedure and trigger. Understand the protection measures of database system; master SQL Server and other application program interface, can do the front design of a management information system with JAVA development tools. 


\section{Curriculum InNOVATION ABILITy Training EXPLORATION}

\section{A. Application driven, stimulate students' interest in learning}

As the saying goes: "A good beginning is half done", "Interest is the best teacher". Therefore, the first class course, do not rush to introduce the theory of application, but stressed that the course of application, through the introduction of familiar to stimulate students' interest in learning, such as highspeed rail ticketing, Taobao shopping, courier documents query, supermarket sales, the creation of "I want to learn" atmosphere. Introduction to the role and task, teaching aim, curriculum and other curriculum, curriculum and employment and the relationship between the experimental environment, project name, curriculum design, curriculum arrangement, let students know, understand the general situation of the course.

Encourage students to develop skills, and actively participate in the database curriculum related certification exam and competition, to lay a good foundation for employment. Pay attention to the art of classroom teaching, practical courses increase experimental projects, mobilize the enthusiasm of students, making full use of E-Learning teaching platform, and strengthen the supervision training happy learning process, let each student love to learn.

\section{B. Teach people to fish, introduced learning methods}

Strengthen the research of education theory and teaching method, pay attention to the teaching method of learning and the cultivation of students' self-learning ability. To establish a "student-centered" teaching philosophy, based on constructivism theory, "Delegate to fish in the fishery as delegate ", how to solve, for preview, review lectures and training combined, timely, independent, carefully complete each work, enhancing students self-learning and the spirit of active exploration and innovation [1].

In addition to the introduction of the teaching course website, conventional reference books, the requirements of curriculum, teachers' various contacts, also provides electronic assisted learning materials, introduces the National Excellent Course "large database (SQL SERVER), MOOC" quality course website, learn to use the excellent teaching resources department.

\section{Perfect the practice teaching system, strengthen the experiment teaching}

In the experiment class, first through the E-Learning teaching platform to carry on the key experiment topic demonstration explanation, the student again single machine experiment pays attention to the student experiment individuality guidance, the common question solution. In practice teaching, it is an integrated practice teaching system which has formed a complete practical teaching system for verifying experiment, designing experiment and integrated curriculum design. Carefully designed experiments (including experiments), clear the purpose and task of each experiment. Ready to work requires students to experiment before class, finish the experiment report, with reporting to debugging and verification, to ensure the correctness of written procedures, improve the ability of self-learning and problem solving, on summarizing and analysis, and improve the experimental report.

\section{Integrated curriculum design, focus on innovation and application ability training}

Curriculum design focuses on training students to analyze and solve problems, theory guiding practice, thinking of innovative ability, is an important part of the curriculum teaching. The combination of different professional courses, Delphi program design, selection and creation of students during JAVA programming, Dreamweaver, VB and other web design course instructor joint, starting at eighth weeks, the general arrangement is decorated with a curriculum design. The curriculum design in the group of 3-4 people, organization design and development of a small database application system requirements, system function and interface design of the curriculum in accordance with the requirements of the teachers do, the background using SQL Server database construction.

In the database design stage, clear requirements such as database design, the design must be more than 4 relations, each relationship must specify the primary key, meet the entity integrity and referential integrity, design more than three storage process and design a call, above the trigger, the establishment of more than two characters, the basic function of the system implementation, data entry modify, delete, data integrity checking, query and report printing.

Through the combination of curriculum design, students will learn the knowledge mastery; apply to the actual development to improve their practical ability, cultivating students' innovative ability and comprehensive application ability of knowledge.

\section{E. Way of examination, pay attention to the process of learning}

Usually implement the examination record system, course attendance, homework, internship report, curriculum design, etc. the five part test, according to the $30 \%$ into the final results. Operation is mainly theoretical knowledge and application, the implementation of the main examination procedures, curriculum design for the comprehensive design, by the two teachers to give results. The final test required to write a SQL command in the back of each problem, and the results of screenshots posted on the SQL command back to "number + name" named WORLD file, and uploaded to the FTP server specified folder. The final written examination questions have accounted for $70 \%$, selection, test and application, short answer questions, command programming, reading program and other forms, to further strengthen the comprehensive knowledge of master degree. Will further increase the proportion of grades, students focus on the learning process and the accumulation of knowledge and gradually improve the application ability.

\section{F. Enrich the teaching resources, expand the learning space}

The course for the establishment of the curriculum teaching team, to develop a regular study plan, the implementation of collective lesson preparation, play a team strength, make full use of network teaching platform, and constantly enrich the teaching resources. Course materials all the Internet, to achieve 
online Q \& A, online testing, job submission system, etc. Students can see the teacher after the assignment of homework and curriculum design, completed in the specified time can be submitted online. Make full use of multimedia teaching, making multimedia courseware, each semester all add a large number of practical examples, rich in content, covering the knowledge points, test. Open up the column to expand the knowledge, to encourage students to deepen the ability of the course to learn, improve practical application ability. Meet the individual learning needs of different students, broaden the learning channels of students, extend the classroom, training students to learn the initiative and innovation, improve the teaching effect.

\section{The SElection And Construction Practice of Course MATERIALS}

\section{A. Selection of textbook}

After repeated selection and updating the database technology textbook, found some problems, such as: the principle of the database part no explanation or insufficient to explain the design of the database is not clear; some knowledge of operation without explanation, and use directly in the example, which causes students to understand concepts hardly; Some examples use the following to talk about the knowledge, the level of textbook need to be adjusted; Delphi program design is a compulsory course for all the students of our Department, We did not found the textbook which use Delphi as the front of the curriculum design case database, It is difficult for students to learn. We think that the teaching material should embody the organic combination of the principle, method, technology and application, and cultivate the students' ability of database operation and database design, and apply the theory to the practical ability of comprehensive innovation.

\section{B. Practice of teaching material construction}

Based on the training program of Applied Talents in college, the first edition of "SQL Server 2005 database technology" teaching materials was published by Tsinghua University Press in 2010. Using SQL Server 2005 as the development platform describes the basic principles of the database, platform functions and development and application of technology. According to the teaching focus and requirements, chapters, summary, training programs and exercises "style of writing, beginning with awareness, learning problems, the summary is helpful for learning content through induction, training and exercises to help readers master the relevant training and operation skills, programming design and development based on technology; the application of the book, the use of a unified JXGL database, to facilitate teaching and learning; theory of knowledge points is outstanding, pay attention to the cultivation of practice ability, command application, difficult, often wrong explain knowledge points clear, concise language, structured, abundant examples of cases were verified by experiments, and training a large number of projects with maps; each chapter has exercises, with answers, easy to learn and improve.
The textbook is divided into three parts, the first part is the SQL Server database, describes the basic principle of database theory and database design of the whole process of relational database, describes the required knowledge of database application system development, management, database and table query and view, indexing, transaction and lock; Second part is SQL Server database programming, From the perspective of program and system development, focusing on the T-SQL programming, stored procedures, data integrity and trigger, and user-defined function and so on ;Finally, from the perspective of software engineering, Delphi is used as the desktop tool to explain in detail the development of "case of student information management system", to achieve the organic integration of the database and desktop development tool, highlighting the comprehensive application. [2].

Because the SQL Server update, The textbook was revised in 2016, "Database technology training course (Second Edition)", the current SQL Server 2014 as the development platform, readjust the sections of content, followed by the software programming practice, case third part course redesign, the popular Visual Studio development tools are selected as the development program can be more efficient to build secure, scalable applications [3].

\section{Use and effect of textbook}

Our school of computer science and technology, computer application technology, computer network technology, such as a number of professional uses of the textbook. Through the joint efforts of the group, as the follow-up courses such as: software engineering, JAVA program design and graduation design of the teaching of the course is very satisfactory, provided strong support that the principle and application of database for the teaching of these courses. For nearly three years, students participate in the contest, "Qilu Software Chinese software cup software design contest and other related students winning the competition more than 30 shows that students' ability of innovation and application constantly improve, also proved the teaching effect is good.

The textbooks were used by the university such as the Shandong Youth University Of Political Science, Shandong University of Finance and Economics, Qufu Normal University, Taiyuan Institute of Technology, Shaanxi Normal University ,etc. After communication with the Tsinghua University press editor, other university teachers thought that the arrangement of the textbook's contents is reasonable, the structure is rigorous, the level is clear, the example is rich, easy to teach and easy to learn, Closely combined with the talent training program, Focus on the integration of leading and successor courses, pay more attention to the cultivation of students' comprehensive application ability of practice and innovation, teaching materials compiling style, case selection and supporting the courseware, experiment, curriculum design materials respond better, hope to continue to adopt, in January 2015 revised edition printed one times.

\section{CONCLUSION}

Our database teaching team has 6 people, teachers with reasonable structure, has carried out a series of research work 
of database technology, built the database principle and application of the high quality curriculum, taking data mining research, supermarket image data mining based on a number of provincial school teaching and scientific research project, a textbook published by Tsinghua University Press etc.

Study on the teaching reform is a long process, we will continue to participate in discussion of course meeting, learn from the national teacher, draw lessons from excellent teachers, continuous exploration, development track database, application development with industry, reinforcement of the construction of "dual-qualification" teaching staff, and continuously enhance teaching effectiveness.

\section{REFERENCES}

[1] Jiang Xiuying. Teaching reform of data structure course based on innovation ability [J]. Journal of Langfang Teacher's College (NATURAL SCIENCE EDITION), 2011 (4) 103:105.
[2] Jiang Xiuying, Lv Jiaguo, Chi Qingyun Server.SQL 2005 database technology [M]. Beijing: Tsinghua University press, 2010.12.

[3] Jiang Xiuying, Chi Qingyun, Lu Jia Guo. Database technology training tutorial (Second Edition) [M]. Beijing: Tsinghua University press, 2016.09.

[4] Lu Yan, Zhang Chen. In the training of application ability oriented teaching reform of database courses to explore [J]. Journal of Mudanjiang Institute of education, 2016 (7): 97-98.

[5] Wang Xiaodong, Wu Yaqin. The practice of teaching reform of database principle course to explore the $[\mathrm{J}]$. education and teaching forum, 2014.11:45-46.

[6] Huang Decai, Luyi red, Wang Song, Gong Weihua, Xiong Lirong. The fine course of database principle and application of textbook construction of [J]. computer education, 2011 (9): 129-132.

[7] Li Chao, Xie Kunwu. Study on the teaching reform of database in computer applied talents training [J]. computer age, 2016 (2): 93-95.

[8] Zhu Ge. Research on teaching reform of database design and application course [J]. Heilongjiang education, 2016 (5): 37-38. 